\title{
The effect of 6-week core stability training on core endurance and physical performance in professional rugby players: A randomized controlled pilot study
}

\author{
Chamila S. Senavirathna ${ }^{1}$, Anuja P. Mallawaarachchi², Aranjan L. Karunanayake ${ }^{3}$, \\ Sampath Gunawardena ${ }^{4}$ \\ ${ }^{1}$ Lecturer, Department of Physiotherapy, Faculty of Allied Health Sciences, Sir John Kotelawala Defence University, ${ }^{2}$ Senior \\ Instructor, Department Physical Education, University of Peradeniya, ${ }^{3}$ Professor, Department of Anatomy, Faculty of \\ Medicine, University of Kalaniya, ${ }^{4}$ Professor, Department of Physiology, Faculty of Medicine, University of Ruhuna, Sri Lanka
}

Background: Core stability training (CST) is used to enhance sports performance. The relationship between core endurance and physical performance in rugby players had not been evaluated before in Asia. Aims and Objectives: This study aims to determine the effects of a 6-week specific CST program on the core endurance and physical performances (speed, upper body power, lower body power, and agility) following a CST intervention in male rugby players. Materials and Methods: Professional rugby players ( $n=8$, intervention and $\mathrm{n}=8$, control) were randomly selected. Mean (SD) age, height and weight of intervention group were $25.25(2.4)$ years, $1.64(0.03) \mathrm{m}$, and $69.6(14.9) \mathrm{kg}$, respectively. In the control group, corresponding values were 29.75 (4) years, $1.66(0.04) \mathrm{m}$, and 72.3 (19.1) $\mathrm{kg}$, respectively. Intervention group was trained CST sessions complementary to the usual physical training, 3 times/week for 6 weeks. The control group followed the usual physical training. Subjects were tested for four physical performances (using $40 \mathrm{~m}$ sprint, vertical jump, $3 \mathrm{~kg}$ medicine ball put, and agility $T$ tests) and four core endurance tests (back extension, abdominal fatigue [AF], and left and right bridges). Results: AF, left bridge, right bridge, and total core endurance were significantly increased in the intervention group $(\mathrm{P}=0.028, \mathrm{P}=0.006, \mathrm{P}=0.008$, and $\mathrm{P}=0.001$, respectively $)$. Agility and $\mathrm{AF}$ were increased significantly in the control group $(P=0.048, P=0.027)$. The right side bridge endurance $(P=0.024)$ was significantly increased in the intervention group compared to the control group. Conclusion: The results suggest that the CST improves core endurance without improving physical performances in rugby players.

Key words: Core stability; Physical performance; Rugby players
Access this article online

Website:

http://nepjol.info/index.php/AJMS DOI: $10.3126 /$ ajms.v12i11.38816

E-ISSN: 2091-0576

P-ISSN: 2467-9100

Copyright (c) 2021 Asian Journal of Medical Sciences

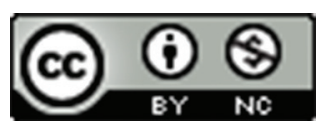

This work is licensed under a Creative Commons Attribution-NonCommercial 4.0 International License.

\section{INTRODUCTION}

Rugby is a physically demanding, high-intensity team sport that is played professionally in many countries worldwide. ${ }^{1}$ It is regarded as a contact and collision sport, played at amateur, semiprofessional and professional levels. The physical conditioning programs prescribed for rugby players usually consist of aerobic fitness training, resistance training (for strength and power development), and speed and agility sessions, along with skill and tactical development sessions.

Rugby players require a strong core to stabilize the trunk and help maintain correct posture while changing direction at speed and this is essential to efficiently transfer force from the ground during contact phases. Value of the core stability training (CST) in rugby skills highlighted by Cissik, 2002, mentioned that pelvic/spinal stability benefits the 
player in allowing efficient execution of rugby skills and reduces injury risk. ${ }^{2}$ Core stability is the ability of the lumbopelvic hip complex to prevent buckling and to return to equilibrium after perturbation. Willson et al., stated that there is a clear relationship between trunk muscle activity and lower extremity movement and decreased core stability may predispose to injury and that appropriate training may reduce injury. ${ }^{3}$

There is a lack of research looking at the effect of core stability on athletic performance. Although some studies have implied that there is an advantageous effect on performance by improving core stability and strength, these conclusions are largely assumptions based on basic testing. ${ }^{4-6}$ Area of study in performance enhancement by improving the core stability is less in the literature and this study will fill the knowledge gap.

The main purpose of this study is to investigate the relationship between core stability and physical performances in male rugby players. General objective of the study is to assess the effects of a CST program on the physical performance in professional male rugby players.

\section{Aims and objectives}

To assess the effects of a Core Stability Training (CST) program on the core endurance and physical performance in professional rugby players.

\section{MATERIALS AND METHODS}

\section{Study design}

The study design is a randomized control interventional study in which a set of parameters were assessed at baseline level and after 6 weeks of CST in the intervention group of rugby players. Same parameters were assessed in a randomly selected control group of rugby players who went through 6 weeks of usual physical training carried out by rugby players without adding the CST provided to the intervention group. Measurements were taken at baseline and after 6 weeks of physical training.

\section{Subjects}

After giving their informed written consent, eight male rugby players (mean \pm SD age, stature, and body mass of $25.25 \pm 2.4$ years, $1.64 \pm 0.03 \mathrm{~m}$, and $69.6 \pm 14.9 \mathrm{~kg}$, respectively) volunteered to participate in the training program which consisted of static and dynamic CST sessions complementary to the usual physical training, 3 times/week for 6 weeks as the intervention group. Another eight rugby players (mean $\pm \mathrm{SD}$ age, stature, and body mass of $29.75 \pm 4.0$ years, $1.66 \pm 0.04 \mathrm{~m}$, and $72.3 \pm 19.1 \mathrm{~kg}$, respectively) with the written consent selected as the control group and they followed the usual physical training provided to rugby players but did not undergo the CST designed for the experimental group. This study was approved by the Ethics Review Committee of the Faculty of Medicine, University of Ruhuna (2018/P/071), Sri Lanka, and the Sri Lanka Clinical Trials Registry (SLCTR/2019/036).

\section{Procedures}

All the players with a minimum of 3 years of experience in the field of rugby were selected to the study. Training methods, training schedules, trainer, and the coach remained the same for the selected players. Intervention group completed 6 weeks of CST program in addition to their normal rugby training and all the participants were subjected to the same testing protocol before and after the 6-week program. Baseline measurements and tests were carried out on all subjects by an independent person to avoid investigator bias on the first 2 weeks of the study. Then, the CST program was implemented for the intervention group for 6 weeks by the coaches with the principal investigator, along with the routine training program. Post-measurements and tests were taken from both groups at the end of 6 weeks by the same independent person.

\section{Measurements and tests}

\section{Anthropometric measurements Standing height}

Body height was measured to the nearest centimeter using a stadiometer. Measurements were made with the subjects standing barefoot, heel together with arms hanging naturally by their sides while looking straight ahead. ${ }^{7}$

\section{Body weight}

Body weight was measured to the nearest $0.1 \mathrm{~kg}$ using a calibrated electronic scale (Tanita Body Composition Analyzer/Scale, Tanita UK Ltd., Yiewsley, UK) with the subjects in lightweight clothing and barefoot.

\section{Core stability measurements Core endurance}

McGill has identified a number of tests as valid and reliable for showing torso muscular endurance. ${ }^{6}$ The four tests, back extension (BE) test (Figure 1), abdominal fatigue (AF) test (Figure 2), and left and right bridge tests (Figure 3), were shown to have reliability coefficients of between 0.97 and 0.99. Maximum holding time was taken in seconds in each test. Sum of all the core muscular endurance were taken as the total endurance for the analysis.

\section{Physical performance test measurements Agility t-test (ATT)}

The ATT was used to determine the agility performance. Players' agility was evaluated using the ATT according to 


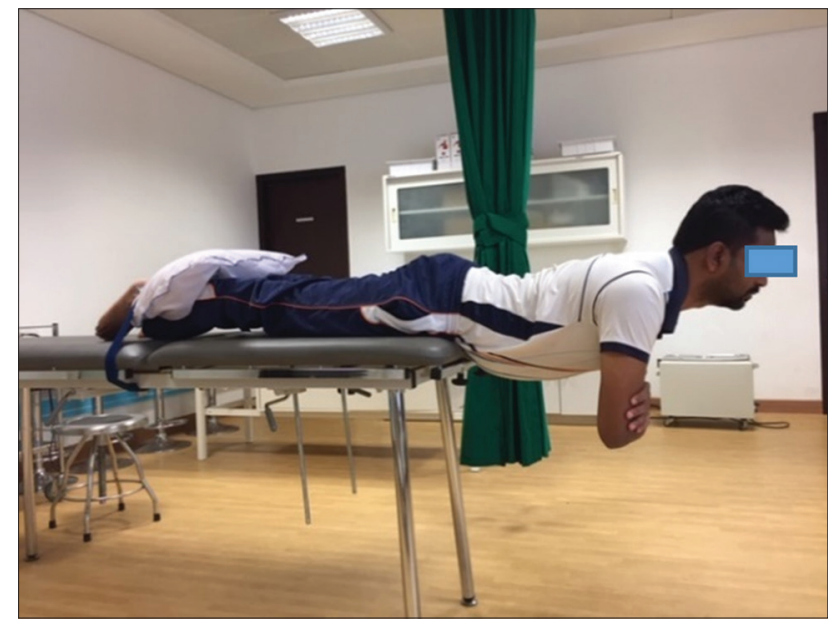

Figure 1: Back extensor test

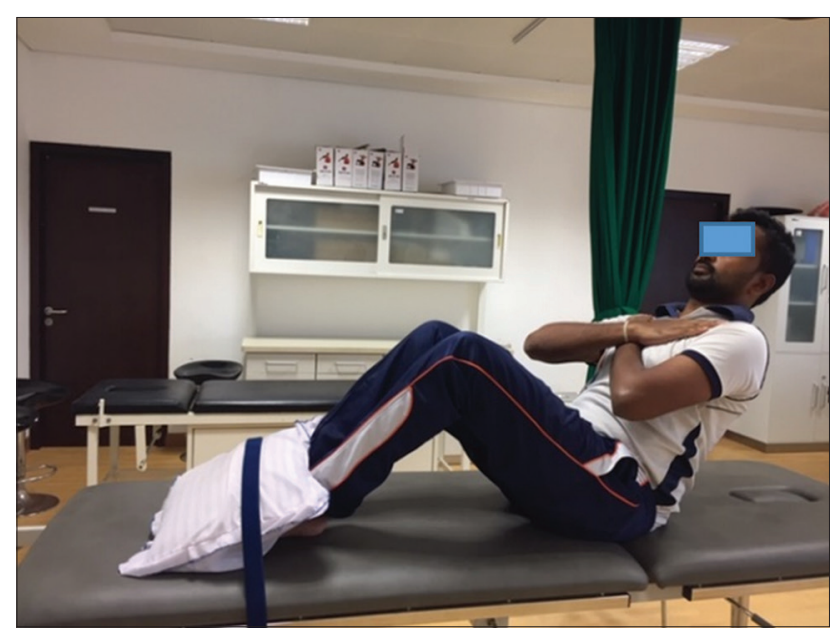

Figure 2: Abdominal fatigue test

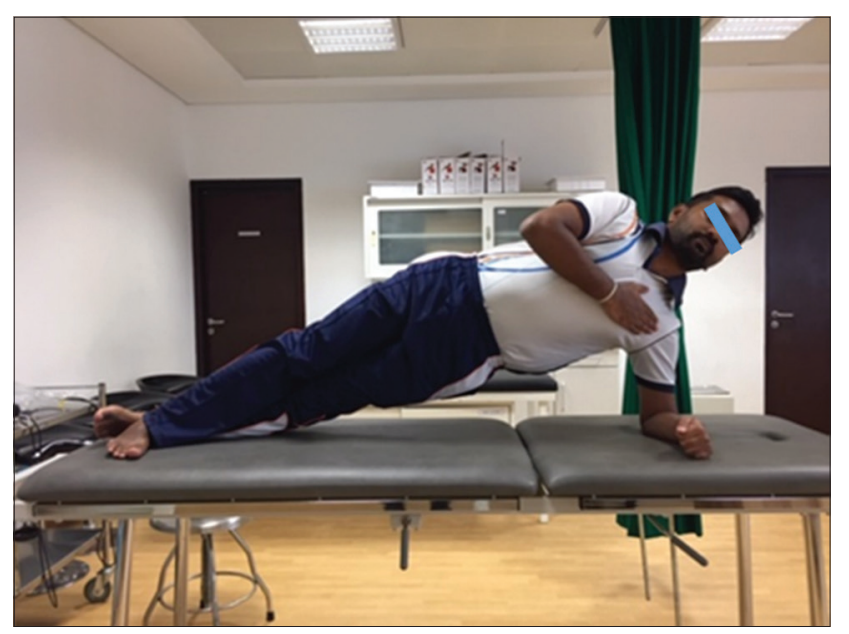

Figure 3: Side bridge test

the method of Asadi. ${ }^{8}$ The t-test was also performed on the rugby field, and subjects were again instructed to perform the test in their rugby boots. The subjects were instructed to sprint from a standing starting position to a cone $9 \mathrm{~m}$ away, followed by a side shuffle left to a cone $4.5 \mathrm{~m}$ away.
After touching the cone, the subjects side shuffled to a cone $9 \mathrm{~m}$ away and then side shuffled back to the middle cone. The test was concluded by back pedaling to the starting line. The test score was recorded as the best time of two trials, to the nearest $0.01 \mathrm{~s}$. A 2 min rest period was allowed between each trial. Subjects were disqualified if they failed to touch the base of any cone, crossed the one foot in front of the other, or failed to face forward for the entire test. The testretest reliability for the two measurements of the pre-test day was found to be 0.89 and for the post-test day 0.80 .

\section{Upper body (UB) explosive power}

UB explosive power (UBP) was measured by means of the seated $3 \mathrm{~kg}$ medicine ball put test (MBPT) according to the method of Ball et al., 9 The seated MBPT was regarded as an objective $(\mathrm{r}=0.99)$, valid $(\mathrm{r}=0.77-0.90)$, and reliable test $(\mathrm{r}=0.77-0.99)$ to assess the muscular power of the arms and shoulder girdle. ${ }^{9}$

Subjects were instructed to sit up straight with the upper back area against a wall and the legs extended straight to the front. Subjects were not allowed to move the upper back from the wall during the put action with a view to eliminate the use of momentum. Subjects were instructed to place the palms of their hands on the sides of the ball in a manner as to prevent cocking of the wrists. When ready, the subjects balled back against the chest and forcefully pushed it forward and upward. The arc of the ball was controlled by a ring that positioned $2 \mathrm{~m}$ in front of the subject at a height that controls the angle of release to be approximately $45^{\circ}$. Subjects were given two practice trials followed by three maximal efforts with a rest period of $30 \mathrm{~s}$ between each effort. The best distance of the three maximal efforts was recorded to the nearest centimeter.

\section{Lower body (LB) explosive power}

LB explosive power (LBP) was measured by means of the vertical jump test (VJT) ${ }^{10}$ Reach height was measured on all participants before VJT. Subjects stood flat-footed and reached as high as possible with one arm. The highest point reached on the Vertec was considered reach height. Individuals were allowed one arm swing down and up while jumping off both feet and reaching as high as possible with one arm to displace the highest possible vane on the Vertec. Jumping height was calculated as the distance from the highest point reached during the reach height and the highest point reached during the jump. The subjects had performed two trials with a $30 \mathrm{~s}$ rest period between each trial. The best distance of the two trials was recorded for the purpose of data analysis.

\section{$40 \mathrm{~m}$ speed test}

Sprint times were assessed using timing lights (Fusion Smart Speed Timing Gates System, Queensland, Australia). After 
a thorough warm-up of dynamic flexibility and running at progressively faster speeds, participants completed a two $40 \mathrm{~m}$ sprints through the timing lights with at least $2 \mathrm{~min}$ of passive recovery. Participants were instructed to start the sprint from a standing split stance (left leg forward) and to maintain their effort past the last timing light. Sprint time was collected at 40 min. ${ }^{11}$

\section{Statistical analysis}

Data entered and validated in a Statistical Package for the Social Sciences (SPSS) (SPSS version 21.0) database. Change in physical performance tests was considered as major outcome variables (agility, speed, UBP, and LBP). Alterations of the measurements assessed in pre-test data at first sessions and post-test data after 6 weeks of exercise program in both the control and intervention groups. The mean differences in the outcome variables calculated in both the control and intervention groups in pre- and post-training were analyzed to see the difference in groups.

Descriptive statistics were performed on all data. Nonparametric Wilcoxon signed-ranks test performed to identify the significance difference between pre and post physiological parameters within the intervention group and control group. Non-parametric MannWhitney U-test performed to identify the significance of variables between the intervention group and control group.

\section{RESULTS}

Mean (standard deviation) of age and BMI of the intervention group were 25.25 (2.4) years and 25.62 (5.1) $\mathrm{kgm}^{-2}$, respectively. In the control group, corresponding values were 29.75 (4) years and 25.87 (6.1) $\mathrm{kgm}^{-2}$, respectively.
Body mass index (BMI) was not significant in premeasurements in both groups $\mathrm{P}>0.05$ and it was considered as equal groups with the same BMI range.

Core and performance variables of the control and intervention groups are listed in Table 1. AF, left SB, right $\mathrm{SB}$, and total core endurance were significantly different between week 0 and week 6 in the intervention group. The control group showed significant differences in $\mathrm{AF}$ and agility between week 0 and week 6 (Table 1).

Comparison of core stability and performance variables of the control and intervention groups is listed in Table 2. The right SB test results revealed a significant difference in the intervention group compared to the control group.

\section{DISCUSSION}

The purpose of this study was to evaluate the effectiveness of a 6-week CST on core endurance and physical performance in professional rugby players. To the best of our knowledge, the present investigation was the first to evaluate the effect of a CST program on physical performance in rugby players in Asia.

Our study incorporated McGill's core stability tests. These tests were designed to measure muscle endurance of the core musculature. Muscles that can sustain prolonged contractions are less likely to fatigue and can thus continue to provide support to the torso overtime, reducing the chance of injury or to maintain sport performance. Therefore, greater core muscle endurance should correspond with a greater capacity to do work. Because the core strength/stability tests used in the study had reported reliability coefficients of $\geq 0.98$, we believe that McGill's assessment of core strength is accurate $;{ }^{6}$ however, it may

\begin{tabular}{|c|c|c|c|c|c|c|}
\hline \multirow[t]{2}{*}{ Variable } & \multicolumn{3}{|c|}{ Control group } & \multicolumn{3}{|c|}{ Intervention group } \\
\hline & $\begin{array}{c}\text { Pre } \\
\text { mean } \pm S D\end{array}$ & $\begin{array}{c}\text { Post } \\
\text { mean } \pm S D\end{array}$ & $P$ value & $\begin{array}{c}\text { Pre } \\
\text { mean } \pm S D\end{array}$ & $\begin{array}{c}\text { Post } \\
\text { mean } \pm S D\end{array}$ & $P$ value \\
\hline Agility (s) & $11.48 \pm 0.69$ & $11.00 \pm 0.63$ & $0.04^{*}$ & $11.24 \pm 0.65$ & $10.85 \pm 0.65$ & 0.12 \\
\hline UBP $(\mathrm{cm})$ & $5.09 \pm 0.59$ & $5.16 \pm 0.53$ & 0.40 & $5.25 \pm 0.44$ & $5.34 \pm 0.48$ & 0.42 \\
\hline $\operatorname{LBP}(\mathrm{cm})$ & $715.37 \pm 171.63$ & $726.75 \pm 133.62$ & 0.63 & $708.87 \pm 172.10$ & $743.75 \pm 161.32$ & 0.06 \\
\hline Speed (s) & $5.61 \pm 0.45$ & $5.62 \pm 0.37$ & 0.93 & $5.50 \pm 0.33$ & $5.45 \pm 0.32$ & 0.59 \\
\hline $\mathrm{BE}(\mathrm{s})$ & $96.25 \pm 28.78$ & $100.25 \pm 24.99$ & 0.80 & $108.00 \pm 38.19$ & $114.50 \pm 27.01$ & 0.51 \\
\hline $\mathrm{AF}(\mathrm{s})$ & $102.37 \pm 47.58$ & $122.62 \pm 48.21$ & $0.02^{*}$ & $102.37 \pm 37.12$ & $150.00 \pm 59.52$ & $0.02^{*}$ \\
\hline Left SB (s) & $76.37 \pm 36.20$ & $92.12 \pm 31.99$ & 0.21 & $88.87 \pm 21.45$ & $109.62 \pm 26.33$ & $0.00^{*}$ \\
\hline Right SB (s) & $84.25 \pm 31.53$ & $91.0 \pm 20.98$ & 0.28 & $83.50 \pm 24.61$ & $118.25 \pm 29.69$ & $0.00^{*}$ \\
\hline Total core endurance (s) & $359.25 \pm 124.62$ & $406.00 \pm 105.60$ & 0.14 & $382.75 \pm 66.25$ & $492.37 \pm 79.84$ & $0.00^{*}$ \\
\hline
\end{tabular}




\begin{tabular}{|c|c|c|c|}
\hline \multirow[t]{2}{*}{ Variable } & \multicolumn{2}{|c|}{ Mean $\pm S D$} & \multirow[t]{2}{*}{$P$ value } \\
\hline & $\begin{array}{l}\text { Control } \\
\text { group }\end{array}$ & $\begin{array}{l}\text { Intervention } \\
\text { group }\end{array}$ & \\
\hline Agility (s) & $-0.47 \pm 0.55$ & $-0.39 \pm 0.63$ & 0.79 \\
\hline $\operatorname{UBP}(\mathrm{cm})$ & $0.06 \pm 0.21$ & $0.08 \pm 0.27$ & 0.88 \\
\hline LBP (cm) & $11.38 \pm 65.22$ & $34.88 \pm 44.92$ & 0.41 \\
\hline Speed (s) & $0.007 \pm 0.23$ & $-0.04 \pm 0.22$ & 0.66 \\
\hline $\mathrm{BE}(\mathrm{s})$ & $13.75 \pm 28.78$ & $6.50 \pm 26.95$ & 0.61 \\
\hline AF (s) & $20.25 \pm 20.56$ & $47.63 \pm 48.79$ & 0.16 \\
\hline Left SB (s) & $15.75 \pm 32.76$ & $20.75 \pm 14.96$ & 0.70 \\
\hline Right SB (s) & $6.75 \pm 16.50$ & $34.75 \pm 26.70$ & $0.02^{*}$ \\
\hline $\begin{array}{l}\text { Total Core } \\
\text { endurance (s) }\end{array}$ & $56.50 \pm 75.21$ & $109.63 \pm 58.24$ & 0.13 \\
\hline
\end{tabular}

not represent how the muscles operate under functional loads and movements.

The results of the study Nesser et al., ${ }^{12}$ suggested that core stability is moderately related to strength and performance in football players. Further, this study suggested that increases in core strength are not going to contribute significantly to strength and power in football players following a CST.

In our study, agility and AF were significantly increased $(\mathrm{P}<0.05)$ in the control group mean that the abdominal component of core endurance has improved even after the regular rugby training. One suggestion can be made that the regular training has an impact on the agility in rugby players.

Core endurance variables (BE, AF, right bridge, left bridge, and total endurance) in the intervention group did not follow the normality and tested with Wilcoxon rank-sum test. According to the results, AF, right bridge, left bridge, and total endurance were increased significantly $(\mathrm{P}<0.05)$ following 6 weeks of CST with the usual rugby training. The control group showed an improvement in AF, whereas the intervention group showed increased core stability in all endurance tests except BE. The above facts revealed an added effect of core stability program on total core endurance of rugby players.

All the core endurance measurements and physical performance variables were compared in groups at the end of 6 weeks. Difference of each variable was taken for the analysis. The right $\mathrm{SB}$ endurance $(\mathrm{P}<0.05)$ significantly increased in the intervention group (Table 2) and this study provided a positive evidence that the core training is necessary for optimal core endurance and should not be dismissed for all sport branches.

A similar study was conducted by Nesser and Lee ${ }^{13}$ to determine the effect of core training program on speed, acceleration, vertical jump, and standing long jump in female soccer players consisting of 20 players as the core training group and 20 players as the control group. In this study, the core training group showed a $3.4 \%, 5.9 \%, 13.3 \%$, and $4.2 \%$ improvement in speed, acceleration, vertical jump, and standing long jump (respectively) $(\mathrm{P}<0.05)$. In conclusion of that study, core exercises were claimed to have improved speed, acceleration, vertical jump, and standing long jump in 18-19-year-old female soccer players. The results of this study suggested that core stability is moderately related to strength and performance. Thus, increases in core strength are not going to contribute significantly to strength and power and should not be the focus of strength and conditioning.

Tse et al., ${ }^{14}$ examined the effectiveness of a core endurance exercise program on rowers. According to the results of the study, the 8-week core endurance training program improved selected core endurance in healthy young men, but the effectiveness of the core intervention on various functional performance aspects was not supported.

Araujo et al., ${ }^{15}$ evaluated the landing kinetics during a drop jump test following a CST intervention in female capoeira athletes. This study provides evidence that trunk dominant CST improves landing kinetics without improving jump height, and authors mention that CST may reduce lower extremity injury risk in female athletes.

These studies suggest that core stability contributes to core endurance but not for physical performance in sports. On the basis of the results of this and other studies, the core endurance has improved in players with the CST but the relationship to sport performance is not supported. However, the challenge of determining the effectiveness of core strength and stability training on sport performance remains.

\section{Limitations of the study}

A limitation to this study was the small sample size. Had a greater number of subjects been available for testing, significant correlations may have been found. Despite the fact that core stability was not supported to increase physical performance in rugby players, it does not warrant neglect of the core. At the same time, it appears that the core is no more important than any other body part. 


\section{CONCLUSION}

It is the authors' opinion that core training is necessary for optimal sport performance and should not be dismissed. Determination of the role of core strength/stability requires additional research and sport-specific means of determining its effectiveness. This study provides evidence that CST improves total core endurance without improving agility, speed, and UB muscle power in rugby players. The results from this study provide coaches and other sport professionals with information and guidelines that enable them to plan and set up more effective CST combined to the sport-specific conditioning programs.

\section{ACKNOWLEDGMENTS}

Authors wish to thank all the volunteer players, coaches, and data collectors for their cooperation and assistance and special thanks to Mr. Ranga Thudugala for his advice for the data analysis. This work was undertaken as partial fulfillment of the requirements for an MPhil degree at the University of Ruhuna, Sri Lanka by Chamila S. Senavirathna.

\section{REFERENCES}

1. Duthie G, Pyne D and Hooper S. Applied physiology and game analysis of rugby union. Sports Med. 2003;33(13):973-975. https://doi.org/10.2165/00007256-200333130-00003

2. Cissik JM. Programming abdominal training, Part I. Strength Cond J. 2002;24(1):9-15. Available from: https://www.paulogentil. $\mathrm{com} /$ pdf/Programming $\% 20$ Abdominal $\% 20$ Training $\% 2$ C $\% 20$ Part\%20I.pdf. [Last accessed on 2021 Aug 01].

3. Willson JD, Dougherty CP, Ireland ML and Davis I. Core stability and its relationship to lower extremity function and injury. J Am Acad Orthop Surg. 2005;13(5):316-325. Available from: https://www. journals.Iww.com/jaaos/fulltext/2005/09000/core_stability_and_its_ relationship_to_lower.5.aspx. [Last accessed on 2021 Aug 01].

4. Faries MD and Greenwood M. Core training: Stabilising the confusion. Strength Cond J. 2007;29(2):10-25. Available from: https://www.proquest.com/scholarly-journals/coretraining-stabilizing-confusion/docview/212526617/se2? accountid=201395. [Last accessed on 2021 Aug 01].
5. Cholewicki $\mathrm{J}$ and McGill SM. Mechanical stability of the in vivo lumbar spine: Implications for injury and chronic low back pain. Clin Biomech. 1996;11(1):1-15

https://doi.org/10.1016/0268-0033(95)00035-6

6. Mcgill SM. Electromyographic activity of the abdominal and low back musculature during the generation of isometric and dynamic axial trunk torque: Implications for lumbar mechanics. J Orthop Res. 1991;9(1):91-103. https://doi.org/10.1002/jor.1100090112

7. Eston R and Reilly T. Kinanthropometry and exercise physiology laboratory manual: Tests, procedures and data: Volume two: Physiology. Milton Park, Abingdon-on-Thames: Routledge; 2001.

8. Asadi A. Effects of six weeks depth jump and countermovement jump training on agility performance. Sport Sci. 2012;5(1):67-70. Available from: http://www.neosportsplant.com/performance/ articles/plyometrics/asadia.pdf. [Last accessed on 2021 Aug 01].

9. Ball, T.E., 1991. Medicine ball put (sitting on the floor) test. Kirby's guide to fitness and motor performance tests, pp.331332.

https://doi.org/10.1519/JSC.0b013e31825770ea

10. Van der Walt KN. Selected Anthropometric, Physical and Motor Performance Predictors of Lower Body Explosive Power in Adolescents: The PAHL Study (Doctoral Dissertation); 2014. Available from: http://www.hdl.handle.net/10394/12207. [Last accessed on 2021 Aug 01].

11. Vaz $L$, Morais $T$, Rocha $H$ and James N. Fitness profiles of elite portuguese rugby union players. J Hum Kinet. 2014;41:235-44. https://doi.org/10.2478/hukin-2014-0051

12. Nesser TW, Huxel KC, Tincher JL and Okada T. The relationship between core stability and performance in division I football players. J Strength Cond Res. 2008;22(6):1750-4. https://doi.org/10.1519/JSC.0b013e3181874564

13. Nesser TW, Lee WL. The relationship between core strength and performance in division I female soccer players. J Exerc Physiol Online. 2009;12(2):21-28. Available from: https://www. researchgate.net/publication/228494628_The_relationship_ between_core_strength_and_performance_in_Division_I_ female_soccer_players. [Last accessed on 2021 Aug 01].

14. Tse MA, McManus AM and Masters RS. Development and validation of a core endurance intervention program: Implications for performance in college-age rowers. J Strength Cond Res. 2005;19(3):547-552. Available from: http://www.fitnessmais. com.br/download/treinamento-funcional(2)/Instability_19.pdf.

15. Araujo S, Cohen D and Hayes L. Six weeks of core stability training improves landing kinetics among female capoeira athletes: A pilot study. J Hum Kinet. 2015;45:27. https://doi.org/10.1515/hukin-2015-0004

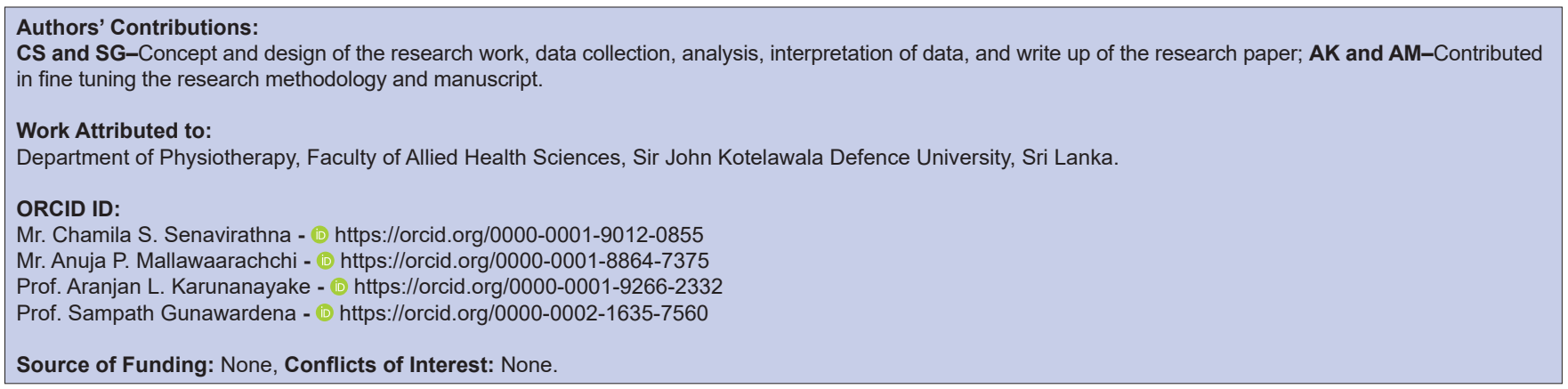

